\title{
Fuzzy Based Failure Mode and Effect Analysis Towards to Risks of Autonomous Maintenance Activities: As a TPM Implementation
}

\author{
Emre BILGiN SARI ${ }^{1}$
}

\begin{abstract}
Manufacturing companies attach importance to Total Productive Maintenance (TPM) applications to extend equipment life and increase efficiency. The recommended applications with TPM are carried out under the pillar activities. Autonomous Maintenance (AM) pillar manage the assignments of the operators to undertake routine maintenance work on machine maintenance. Cleaning, lubrication and control activities are one of the steps of AM pillar and operators need to do them daily. However, there are a number of occupational health and safety risks that operators may face during these activities. Safety (S) pillar which serve as another TPM pillar, deal with occupational accidents and possible situations during TPM applications. AM and S pillars work together to assess the risks that may occur during AM applications. Failure Mode and Effect Analysis (FMEA) is also frequently utilized for risk assessment, but this is criticized in terms of the difficulty in reaching the common point of decision-makers' risk assessment and equal weighting of risk factors. Therefore, it is appropriate to support with the fuzzy logic approach. In this study, the entropy-weighted fuzzy based FMEA method was utilized for identify and prioritize potential risks that may be encountered during the AM activities. Potential risks were revealed and evaluated with the FMEA team. Eleven potential risks were identified in the study. The risk factors of the assessment were weighted by the entropy method. The risk of hand injuring during cleaning the oil below material cutting saw has the highest risk priority.
\end{abstract}

Keywords: TPM, FMEA, Fuzzy-Logic, Entropy, MCDM

Jel Classification Codes: M10, L62, C02

\section{Introduction}

Manufacturing companies, to maintain the existence under the conditions of competition, are looking for leading strategies as cost reduction, quality improvement, correct and timely delivery. The Total Productive Maintenance (TPM) introduced by Nakajima (1988) is one of the most commonly used implementing models for equipment managegement. TPM application focuses on increasing the availability ratio, quality ratio and performance ratio of equipment used in the production area. To achieve these objectives, TPM is gathered with autonomous and planned-preventive maintenance operations. Autonomous maintenance (AM) contains activities that improve equipment efficiency (Tajiri and Gotoh 1992; Nakajima 1988, cited in: McKone, and Weiss, 1998: 340). In TPM applications, autonomous activities are carried out by machine operators, and maintenance work is not considered independent from the operator (Eti et al., 2004: 389). Safety is also crucial in TPM structure, and the risk assessment is a priority issue for the implementation of TPM. The identification of the risks of autonomous maintenance practices are applied by the operators is also a prerequisite for the realization of the company's activities in the world class (Chen, 2013: 5405). These studies require risk analysis for the risks encountered in autonomous maintenance activities.

In the literature and the industrial cases, there are many risk analyzes that have been examined and applied. Risk analyzes are divided into two as qualitative and quantitative approaches. Failure Mode and Effects Analysis (FMEA) is one of the quantitative methods. In 
risk analysis, FMEA is commonly used to prevent occupational accidents and to eliminate possible problems. Many risk analysis methods such as Fault Tree Analysis, Expected Value Analysis, Sensitivity Analysis only assess the probobility and severity criteria of the failures. The FMEA method also uses the previously recognizable value of negativities, unlike other methods. FMEA is a technique that aims to determine the errors and dangers in the system without causing an accident and to start to improvement from the top priority (Liu, et al., 2012: 12297). In determining the degree of probability, severity and detectability, fuzzy logic can be applied to the FMEA method in order to treat subjective or qualitative information in a coherent and logical manner (Sharma, 2005: 991). Fuzzy based FMEA method is used to improve quality and maintenance work (Souza, et al., 2008; Sharma, et al., 2010; Selim, et al., 2016).

In this article, to determine the risks that may occur during autonomous maintenance activities, the opinions of experts were taken. The risk assessment team consisting of occupational health and safety specialist, autonomous maintenance officer, maintenance manager and machine operator have been identifed as experts. In the second part of the article literature studies are given. The third chapter describes the fuzzy based FMEA methodology. In the fourth chapter, the application work and the results obtained are shared and the improvement steps of these failures are decided. In the last part, conclusion and recommendations are presented.

\section{Literature Review}

Total Productive Maintenance (TPM), is an evolution of the methodology that obtained after years of researches on reactive-protective-preventive works on equipment maintenance and reliability (McKone, and Weiss, 1998: 337). The main objective of TPM, which is to increase the availability and overall equipment efficiency, is based on the application pillars shown in Figure 1 (Wakjira, and Singh, 2012: 29; Venkatesh, 2007: 7, Rodrigues, and Hatakeyama, 2006: 277).

Autonomous maintenance is referred to as the Japanese "Jishu Hozen " as one of the TPM pillars and is depend on the idea that if operators are involved in minor maintenance work, there will be more free time for capable maintenance staff to attend to more technical repairs and value-added works. With autonomous maintenance, operators are obliged to perform simple daily activities such as cleaning, lubrication, visual inspection, tightening of loosened bolts, etc. to prevent equipment failure. (Wakjira, and Singh, 2012: 29; Singh, et al., 595).

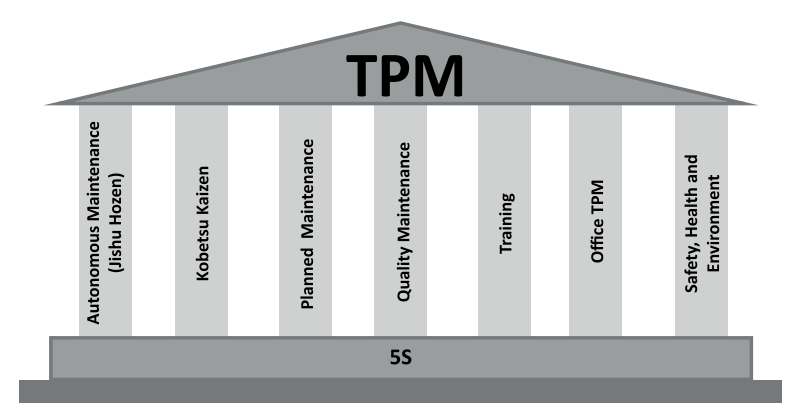

Figure 1:TPM Temple and Pillars

Safety, Health and Environment pillar has an important place in TPM structure. Shirose (1992) uses the term "the maintenance of peace of mind" when describing this pillar (Pomorski, 2004:62). Safety, Health and Environment pillar which aims the zero accidents, focuses on creating and managing a secure workplace. For this purpose, it works interactively with other pillars of TPM (Venkatesh, 2007: 18).

The TPM studies which is conducted with a systematic methodology, are closely related to the reliable operations of manufacturing. The reliability and availability of the operational systems depend on the TPM studies which is continued as reliability, availability and maintainability themes. In the studies supported by TPM, some quality control tools such as Root Cause Analysis (RCA), Failure Mode and Effect Analysis (FMEA) are also utilized for the equipment control (Sharma, et al., 2007: 526). In their study, Sharma, et al. (2007) proposed that RCA and FMEA methods could be used for maintenance or replacement decisions under cost constraints. Zeng, et al., (2010), examined FMEA method within the scope of integrated management systems. Keay, and Borycki, (2010), used FMEA method to evaluate the security. Chen (2013) developed an autonomous preventive maintenance program by using RCA and FMEA. Chong, et al. (2015) aimed to improve the Overall Equipment Efficiency (OEE) by applying FMEA for maintenance activities. Jamshidi, et al. (2015) used the FMEA method for fuzzy risk - based maintenance framawork for prioritization of medical devices. The risk crietia for these devices are listed as visibility, detection via automatic diagnostic aids, detection after an inspection and scheduled inspection. Bao, et al. (2017) applied FMEA integrated with AHP method for evaluating the risks of occupational health and safety. 
FMEA is an approach, which is associated with proactive regulation, and it is used to emphasize the avoiding to the problems rather than finding solution after failure. The FMEA method is implemented by establishing a risk priority number (RPN) to determine the importance of the situation or the rating of risks. However, various methods have been proposed in the literature to determine the occurrence, severity and detectability degrees used to construct the RPN of risk or error. Some approved techniques like Grey theory (Chang, et al., 1999; Chang, et al., 2001), AHP (Braglia, 2000), TOPSIS (Braglia, et al., 2003), DEA (Garcia, et al., 2005; Chin, et al., 2009), DEMATEL (Seyed-Hosseini, et al., 2006), AHP \& PROMETHEE (Ozveri and Kabak, 2015), Fuzzy VIKOR (Liu, et al., 2012), Fuzzy TOPSis (Kutlu and Ekmekçioğlu, 2012) Fuzzy AHP (Kutlu and Ekmekçioğlu, 2012; llangkumaran, et al., 2014), were used with FMEA. In addition, Liu (2016) have studied FMEA using uncertainty theories and MCDM methods. In addition, in the FMEA studies occurrence, severity and detectability values may not be crisp numbers. In these case, fuzzy FMEA is applied.

In the literature, there are many applications of fuzzy FMEA. Immawan, et al., (2018) used fuzzy FMEA for the assesment of operational risks of book production services. Dağsuyu, et al., (2016) applied fuzzy FMEA in sterilization unit risk analysis. Tay, and Lim, (2006) constituted fuzzy RPN process. In this study, fuzzy- based FMEA method will be used to evaluate the risks that may occur during autonomous maintenance activities in TPM implementation. The use of fuzzy approach is important for the purpose of promoting the FMEA method, which is frequently referred to in the studies, in also uncertanity conditions. In addition, FMEA has been used in conjunction with several multi-criteria decision-making techniques, but not with fuzzy entropy for autonomous maintenance activity safety risks. For this reason, this study differs from the previous studies. The next part was created to explain methodology.

\section{Methodology}

\subsection{Failure Mode and Effect Analysis}

Failure Mode and Effect Analysis (FMEA) is an analysis method that develops proactive solutions to take precautions by predicting the risks. FMEA which developed by the US Army and first used in the development of flight control systems in the early 1950s, has focused on system and equipment failures. Then the method that used by some state institutions such as NASA, has become widespread in industrial applications with the use of fuel tanks by Ford Motor Company in 1980s for design faults (Chang et al. 1999: 1072; Sankar, and Prabhu, 2001: 325). FMEA is used to eliminate the losses that may occur as a result of the error to the customer. Potantiel failures can be arising from design, system, process and service are revealed, later occurrence, severity, detection values of these failures are determined, then the risk is evaluated and finally is prioritized (Stamatis, D. H., 2003: 5-10; Chin, et al., 2009: 1769).

Traditional FMEA is a crucial method for detecting and eliminating potential failures to improve the reliability of systems. An inter-functional expert FMEA team is set up to analyze a specific product or system. The initial step of the FMEA is to detect all feasible defect types of product or system. Then, the process is performing on the defect modes defined by taking into account the risk factors and the Occurrence $(\mathrm{O})$, Severity (S) and Detection (D) values are determined. An integer scale of 1 to 10 is used to evaluate three risk factors in traditional FMEA. And risk factors are multiplied to obtain the Risk Priority Number (RPN) as shown in Equation 1 (Stamatis, 2003: 47);

$$
\mathrm{RPN}=\mathrm{O} \times \mathrm{S} \times \mathrm{D} \text {, }
$$

In general, the failures which have higher RPN are considered to be more considerable. According to the RPN values, failure modes (FM) are separated and then corrective actions are taken in to them with high risk levels.

FMEA is an effective and systematic method that can increase the reliability of systems, but this method is criticized in the literature because of its limitations (Braglia, et al., 2003; Sharma, et al., 2005; Tay, and Lim, 2006; Wang, et al. , 2009; Liu, 2016). The common points of these criticisms can be listed as; the relative weight of the risk factors is not considered, and the uncertainty of data does not allow for the computation of the absolute values. In order to overcome these deficiencies of the traditional FMEA some revisions apply like that, the integration of FMEA with fuzzy logic approach and using the factor weighting methods.

\subsection{Fuzzy Logic}

Fuzzy set theory is a tool that was developed by Zadeh (1965) and can be used to describe mathematically complex and ambiguous systems that have difficulty in expressing exact numbers (Yadav, et al., 2003: 660). The application of fuzzy set theory in FMEA ensures several advantages such as the use both quantitative 
and qualitative data together, the direct interpretation of failure modes using linguistic variables. In addition, fuzzy logic is considering the uncertainty of a system affected by many factors (Sharma et al., 2005; Liu, 2016).

The fuzzy set is a set of elements that do not have definite boundaries, have gradual transitions, and have certain membership degrees. This cluster describes a convex structure of fuzzy numbers, each with a membership degree between 0 and 1 (Hu, et al., 2009: 708). The membership function represents the degree of truth in fuzzy logic and the membership functions characterize fuzziness, whether the elements in fuzzy sets are discrete or continuous (Zadeh, 1975). In the definition of membership functions, the proximity of the numbers is used, and the membership functions are usually represented by triangular membership functions and trapezoidal membership functions according to the situation of this neighborhood (Sanayei et al., 2010: 26). In applications, triangular membership functions are preferred mostly for ease of calculation. In this study, triangular membership function is used.

Triangle membership function is defined by three parameters $\mathrm{a}_{1}, \mathrm{a}_{2}$ and $\mathrm{a}_{3}$. Here, $\mathrm{a} 1$ and $\mathrm{a} 3$ respectively, the lower and upper limit values and $a 2$ is the mean value of fuzzy numbers. (Salehi and Tavakkoli-Moghaddam, 2008). Triangle membership function is defined in equation 2 and the triangular form is shown in the Figure 2.

Another important feature of the fuzzy logic approach is that it allows to give meaning to difficult situations with quantitative values. The concept of linguistic variable is very practical in dealing with situations that are too complex to be reasonably defined by traditional quantitative expressions (Zadeh, 1975; cited in: Liu, et

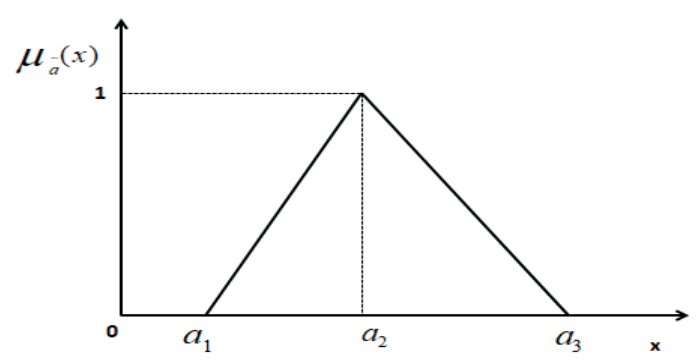

al., 2015: 581). A linguistic variable is a factor whose values are words in language and fuzzy numbers are used for expressing these linguistic variable values. Linguistic variables and the conversion the fuzzy numbers are explained in table 1.

Table 1: Linguistic Variables and Triangular Fuzzy Numbers

\begin{tabular}{ll}
\hline Linguistic Variables & Triangular Fuzzy Numbers \\
\hline Very Low & $(0,0,1)$ \\
\hline Low & $(0,1,3)$ \\
\hline Medium Low & $(1,3,5)$ \\
\hline Medium & $(3,5,7)$ \\
\hline Medium High & $(5,7,9)$ \\
\hline High & $(7,9,10)$ \\
\hline Very High & $(9,10,10)$ \\
\hline
\end{tabular}

Ref: Zadeh, 1975, cited in: Liu, et al., 2016

One of the most important steps of fuzzy logic approach is the process of defuzzication. Defuzzification is performed to obtain a best non-fuzzy performance (BPN) value. Between the techniques like as center of area (COA), mean of maximal (MOM), and a-cut; the COA has practical process and is calculated with equation 3 (Alcan, et al., 2013: 628).

$$
\bar{x}_{0}(\tilde{a})=a_{1}+\left[\left(a_{3}-a_{1}\right)+\left(a_{2}-a_{1}\right)\right] / 3
$$

Following the defuzzication process, it would be appropriate to study another issue called the weak aspect of the traditional FMEA method in the resulting non-fuzzy decision matrix. This issue is about weights of risk factors.

$$
\mu_{a}^{\square}(x)= \begin{cases}\frac{x-a_{1}}{a_{2}-a_{1}}, & a_{1} \leq x \leq a_{2} \\ \frac{a_{3}-x}{a_{3}-a_{2}}, & a_{2} \leq x \leq a_{3} \\ 0, & \text { otherwise }\end{cases}
$$

Figure 2: Triangle Membership Function 


\subsection{Shannon Entropy}

Entropy method is one of the objective weighting methods that can be used to determine the importance order of the criteria. There are various weighting methods that can be used to determine the priority of risk factors. They can be subjective methods like nominal group technique, Pairwise comparison (AHP), Delphi method, Simple Multi-attribute Ranking Technique (SMART) or can be objective methods like Entropy method, Criteria Importance Through Inter-criteria Correlation (CRITIC), mean weight ans so on. In this study objective Entropy method is used.

Shannon Entropy (Shannon, and Weaver, 1947), which is defined as a measure of uncertainty in the knowledge generated in terms of probability theory, is very suitable for measuring the relative contrast densities of the criteria representing the average intrinsic information transmitted to the decision maker (Liu, 2016: 186). Entropy method is one of the objective weighting methods that can be used to determine the importance order of the criteria. The steps of the method are described as follows (Sarı, E..B., 2017: 66)

$\mathrm{X}_{\mathrm{ij}}$; represents the value of alternative i according to the criterion $\mathrm{j}$.

$$
\underset{\text { Step 1: }}{\ldots, \mathrm{n} .} P_{i j}=\frac{x_{i j}}{\sum_{i=1}^{m} X_{i j}}, \mathrm{i}=1,2, \ldots, \mathrm{m} ; \mathrm{j}=1,2 \text {, }
$$

Step 2: $e_{j}=-\frac{1}{\ln m} \sum_{i=1}^{m} P_{i j} \ln P_{i j}$

Each criterion has an entropy value. Here $e_{j}$ shows the entropy value of the criterion $j$.

Adım 3: $W_{j}=\frac{1-e_{j}}{\sum_{p=1}^{n}\left(1-e_{p}\right)}$ The weight values of the criteria are assigned. The sum of the weights is equal

to $1 . \sum_{j=1}^{n} W_{j}=1$.

After the explanation of the methods to be used in the study, the steps to be applied in the research study have been transformed into a model. The steps of the proposed FMEA model supported by fuzzy and entropy are shown in Figure 3.
Form the FMEA Team

Determine The Aim of Risk Assessment

Identify Potential Risks

Evaluation with Linguistic Variables

Language Variables are Converted to Fuzzy Numbers

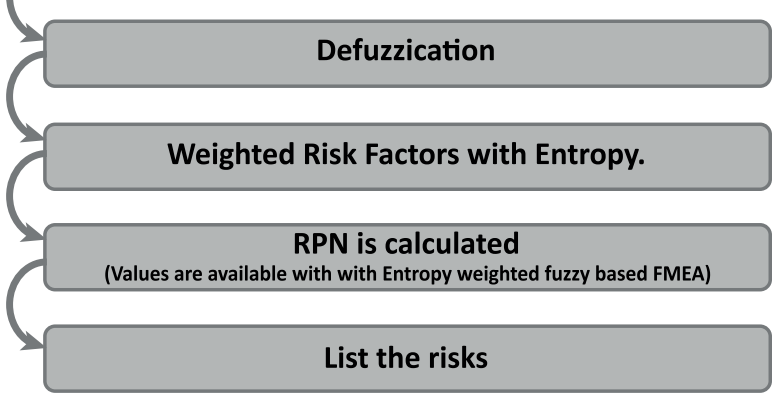

Figure 3: Entropy Weighted Fuzzy Based Failure Mode and Effect Analysis

The first step of the application is the establishment of the FMEA team. The leader of the maintenance team, the autonomous maintenance pillar leader, the machine operator and safety pillar leader are members of FMEA team. Potential risks are revealed according to aim of risk assessment. Linguistic variables are evaluated, and linguistic expressions are transformed into fuzzy numbers. Defuzzication step calculations are applied to fuzzy numbers. Risk factors are weighted by the entropy method. RPN value calculations are made. Risks are listed by prioritizing.

\section{Research Study}

In this section, the proposed approach is implemented in a manufacturing company operating in Izmir. The company produces a speed of 200pcs/min (machine speed depending on the part form) on multi-station machines that make mass production with cold forming method. For an enterprise that produces at this high speed, equipment management and maintenance is very important. The company implements Total Productive Maintenance (TPM) in this regard. Within the scope of the study, Autonomous Maintenance (AM) pillar activities carried out within the framework of TPM implementation are examined. As an Autonomous control step in the planned AM activities, cleaning lubrication and control operations are carried out. In this context, AM checklist was created in the enterprise 
and equipment maintenance services were separated as professional maintenance and autonomous maintenance. The operator is responsible for the operations to be performed with AM. Each operator follows their own autonomous schedule. The operators are likely to encounter some occupational health and safety risks when performing the procedures in the autonomous schedule. For this reason, the Safety (S) pillar formed within the scope of TPM studies should also make an inspection. The leader of the maintenance team, the autonomous maintenance pillar leader, the machine operator and safety pillar leader formed the risk map shown in Figure 4 for the risks that may occur during the cleaning lubrication and control operations of the machine.

After reveal of the risk map, it is required to conduct a study on which risks are more important. The first step is to determine the purpose of the risk assessment team. The risk assessment team agrees to identify high priority risks, but first of all, there is a need to identify the areas of potential risk. The potential risks that may be encountered during the cleaning lubrication and control operation of the machine with the risk map above are explained in Table 2.

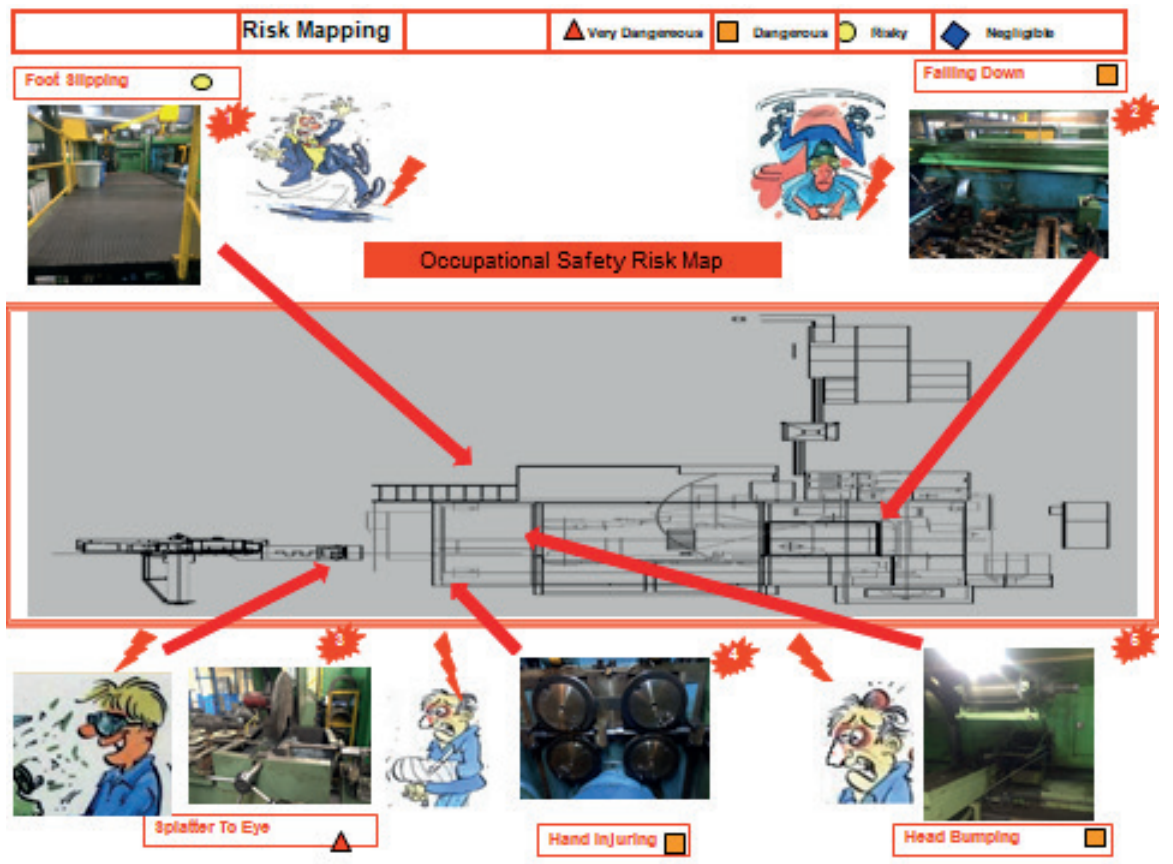

Figure 4: Risk Map of AM Activities on Machine

Table 2: Potential Risk of AM Activities

\begin{tabular}{ll}
\hline NO & Potential Risk of AM Activities \\
\hline FM1 & Falling during cleaning of the transparent surveillance cover of machine \\
\hline FM2 & Finger jam during cleaning transfer system \\
\hline FM3 & Falling during cleaning of the side walls and panels of machine interior part \\
\hline FM4 & Head bumping during manipulator cleaning \\
\hline FM5 & Foot slipping during cleaning of machine outer protection covers and top \\
\hline FM6 & Foot slipping during machine control panel cleaning \\
\hline FM7 & Foot slipping when cleaning measuring stand next to the control panel \\
\hline FM8 & Hand injuring during cleaning the oil below material cutting saw \\
\hline FM9 & Hand jam when cleaning drive rollers \\
\hline FM10 & Head bumping when discharging the canister under the product collection stand \\
\hline FM11 & Foot slipping during draining the canister under the product collection stand \\
\hline FM12 & Hand injuring during cleaning of oil deposits under the product collection table \\
\hline
\end{tabular}


The leader of the maintenance team, AM pillar leader, the machine operator and S pillar leader have expressed their opinions in determining the potential problems. However, there are differences due to different areas of expertise of the decision-makers in determining the risk factor of the identified potential problems. Therefore, the priorities stated by the decision makers on the risks should be taken into consideration with linguistic variability. Fuzzy logic approach is appropriate in this regard. Table 3 presents the responses of the decision makers to the risk factors with linguistic variables.
The linguistic values were first converted to triangular fuzzy numbers. Then, the triangular fuzzy numbers in the form of " $a_{1}, a_{2^{\prime}} a_{3}$ " were calculated as "Min $a_{1^{\prime}}$ $1 / 4 a_{2^{\prime}}, \operatorname{Max} a_{3}$ " to evaluate the values of four decision makers together and the fuzzy matrix was obtained and is shown in Table 4.

In order to defuzzication the total fuzzy matrix, the Center of Area (COA) method was used as described in the methodology chapter, and the decision matrix was reached shown as Table 5.

Table 3: Decision Makers' Answers to Risks Factors of Failure Modes

\begin{tabular}{lllllllllllll}
\hline \multirow{2}{*}{ FM N0 } & \multicolumn{1}{l}{ Severity } & \multicolumn{1}{c}{ Occurrence } & \multicolumn{7}{c}{ Detection } \\
\cline { 2 - 15 } & $\mathrm{DM}$ 1 & DM2 & DM3 & DM4 & DM1 & DM2 & DM3 & DM4 & DM1 & DM2 & DM3 & DM4 \\
\hline FM1 & $M L$ & $L$ & $L$ & $M L$ & $M$ & $M$ & $M L$ & $M H$ & $L$ & $M L$ & $M$ & $M$ \\
\hline FM2 & $M H$ & $M H$ & $M$ & $M H$ & $M$ & $M H$ & $M$ & $M H$ & $M L$ & $M L$ & $M L$ & $M$ \\
\hline FM3 & $M L$ & $M L$ & $L$ & $M$ & $M L$ & $M$ & $M$ & $M H$ & $M L$ & $M L$ & $M L$ & $M L$ \\
\hline FM4 & $M$ & $M$ & $M$ & $M H$ & $M$ & $M L$ & $M$ & $M$ & $L$ & $M$ & $L$ & $M$ \\
\hline FM5 & $L$ & $M L$ & $L$ & $M L$ & $M L$ & $M$ & $M$ & $M$ & $L$ & $L$ & $M L$ & $M$ \\
\hline FM6 & $L$ & $M L$ & $L$ & $M$ & $L$ & $L$ & $M L$ & $M L$ & $M L$ & $M$ & $M$ & $M L$ \\
\hline FM7 & $M L$ & $M L$ & $L$ & $M$ & $L$ & $M L$ & $L$ & $M L$ & $L$ & $L$ & $M L$ & $M$ \\
\hline FM8 & $M$ & $M$ & $M$ & $M H$ & $M H$ & $M$ & $M$ & $M H$ & $H$ & $M H$ & $H$ & $M$ \\
\hline FM9 & $M L$ & $M L$ & $L$ & $M L$ & $L$ & $M L$ & $M$ & $M$ & $M L$ & $M$ & $M$ & $M$ \\
\hline FM10 & $M$ & $M$ & $M L$ & $M H$ & $M L$ & $M L$ & $M$ & $M$ & $M H$ & $M$ & $M L$ & $M H$ \\
\hline FM11 & $H$ & $M H$ & $M$ & $H$ & $M L$ & $L$ & $M$ & $M$ & $H$ & $M H$ & $H$ & $H$ \\
\hline FM12 & $M L$ & $M$ & $M L$ & $M$ & $L$ & $M L$ & $M$ & $M$ & $M L$ & $M$ & $M$ & $M$ \\
\hline
\end{tabular}

Table 4: Total Fuzzy Decision Matrix

\begin{tabular}{llll}
\hline & Severity & Occurrence & Detection \\
\hline FM1 & $(0,2,5)$ & $(1,5,9)$ & $(0,3.5,7)$ \\
\hline FM2 & $(3,6.5,9)$ & $(3,6,9)$ & $(1,3.5,7)$ \\
\hline FM3 & $(0,3,7)$ & $(1,5,9)$ & $(1,3,5)$ \\
\hline FM4 & $(3,5.5,9)$ & $(1,4.5,7)$ & $(0,3,7)$ \\
\hline FM5 & $(0,2,5)$ & $(1,4.5,7)$ & $(0,2.5,7)$ \\
\hline FM6 & $(0,2.5,7)$ & $(0,2,5)$ & $(1,4,7)$ \\
\hline FM7 & $(0,3,7)$ & $(0,2,5)$ & $(0,2.5,7)$ \\
\hline FM9 & $(3,5.5,9)$ & $(3,6,9)$ & $(3,7.5,10)$ \\
\hline FM10 & $(0,2.5,5)$ & $(0,3.5,7)$ & $(1,4.5,7)$ \\
\hline FM11 & $(3,7.5,9)$ & $(0,3.5,7)$ & $(1,8.5,10)$ \\
\hline FM12 & $(1,4,7)$ & $(0,3.5,7)$ & $(1,4.5,7)$ \\
\hline
\end{tabular}

Table 5: Decision Matrix

\begin{tabular}{llll}
\hline & Severity & Occurrence & Detection \\
\hline FM1 & 2,333 & 5,000 & 3,500 \\
\hline FM2 & 6,167 & 6,000 & 3,833 \\
\hline FM3 & 3,333 & 5,000 & 3,000 \\
\hline FM4 & 5,833 & 4,167 & 3,333 \\
\hline FM5 & 2,333 & 4,167 & 3,167 \\
\hline FM6 & 3,167 & 2,333 & 4,000 \\
\hline FM7 & 3,333 & 2,333 & 3,167 \\
\hline FM8 & 5,833 & 6,000 & 6,833 \\
\hline FM9 & 2,500 & 3,500 & 4,167 \\
\hline FM10 & 5,000 & 4,000 & 5,167 \\
\hline FM11 & 6,500 & 3,500 & 7,833 \\
\hline FM12 & 4,000 & 3,500 & 4,167 \\
\hline
\end{tabular}


Entropy method was used in order to prevent risk factors from being taken equally in prioritization and the weights of the risk factors were calculated as WS $=0.418, \mathrm{WO}=0.257, \mathrm{WD}=0.325$. Fuzzy FMEA values, which are formed with the idea that uncertainty and risk priority will change, are associated with entropy weights. Failure Mode (8) "Hand injuring during cleaning the oil below material cutting saw" has emerged as the most important risk. FM8 is also the most crucial risk of classical FMEA. In the table 6, results of entropy weighted fuzzy FMEA and classical fuzzy FMEA is compared.

Table 6: Risk Priority Results

\begin{tabular}{lllll}
\hline \multicolumn{3}{l}{ Fuzzy FMEA } & \multicolumn{2}{l}{ Classic Fuzzy FMEA } \\
\hline Priority & FM & $\begin{array}{l}\text { Entropi } \\
\text { weighted RPN }\end{array}$ & FM & RPN \\
\hline RPN1 & FM8 & 6,201 & FM8 & 210 \\
\hline RPN2 & FM11 & 6,163 & FM11 & 147 \\
\hline RPN3 & FM2 & 5,366 & FM2 & 144 \\
\hline RPN4 & FM10 & 4,797 & FM10 & 100 \\
\hline RPN5 & FM4 & 4,593 & FM4 & 90 \\
\hline RPN6 & FM12 & 3,926 & FM1 & 60 \\
\hline RPN7 & FM3 & 3,653 & FM3 & 60 \\
\hline RPN8 & FM1 & 3,397 & FM9 & 48 \\
\hline RPN9 & FM9 & 3,298 & FM12 & 48 \\
\hline RPN10 & FM6 & 3,224 & FM5 & 24 \\
\hline RPN11 & FM5 & 3,075 & FM6 & 24 \\
\hline RPN12 & FM7 & 3,022 & FM7 & 18 \\
\hline
\end{tabular}

When the classical fuzzy FMEA method and Fuzzy FMEA method were compared, the first 5 failure modes that should be prioritized among the all problems are same. The fact that different decision makers have similar views in linguistic expressions used for these risks contributes to these results. However, the classical method and fuzzy FMEA results do not show any similarity between the problem types with less priority. Because, the rate of neglection for decision makers are different in the situations that are considered to be less hazardous. So that, the results vary from the most to least prominence.

On the other hand, the risk factors are considered to be of equal importance when performing RPN calculation in classical fuzzy FMEA method. However, in this study, the risk factor values were weighted by Shannon Entropy method. The weight of severity risk factor is 0.418 and it is the highest weight between the factors, this is leading to the prominence of fatal defect types in ranking. So, severity risk factor has a decisive role in this study. However, it is still not effective enough to be made prioritized by evaluating alone. Therefore, the effect of other risk factors appears in the calculations.

Identifying the failure modes and prioritizing them is certainly crucial, but the main objective of all these studies is to prepare groundwork for precautions and improvements of failures. Following the Fuzzy FMEA study, the results were evaluated by decision makers. And for all twelve potential risk, action list have been initiated. In addition, there are issues that should be done in common for all risks. Table 7 shows what requires to be done for prevention and improvement.

Table 7: Precaution and Improvement of Failure Modes

\begin{tabular}{|c|c|}
\hline $\begin{array}{l}\text { Failure } \\
\text { Mode }\end{array}$ & Precaution and Improvement \\
\hline FM1 & Visual warning form is hanged on the line. Protective work shoes and gloves will be used. Make sure that the ground is dry. \\
\hline FM2 & Visual warning form is hanged on the line. Protective work shoes glasses and gloves will be used \\
\hline FM3 & Visual warning form is hanged on the line. Protective work shoes and gloves will be used. Make sure that the ground is dry. \\
\hline FM4 & Visual warning form is hanged on the line. Protective work shoes glasses and gloves will be used \\
\hline FM5 & Visual warning form is hanged on the line. Protective work shoes and gloves will be used. Make sure that the ground is dry. \\
\hline FM6 & Visual warning form is hanged on the line. Protective work shoes and gloves will be used. Make sure that the ground is dry. \\
\hline FM7 & Visual warning form is hanged on the line. Protective work shoes and gloves will be used. Make sure that the ground is dry. \\
\hline FM8 & Visual warning form is hanged on the line. Protective work shoes glasses and gloves will be used \\
\hline FM9 & Visual warning form is hanged on the line. Protective work shoes glasses and gloves will be used \\
\hline FM10 & Visual warning form is hanged on the line. Protective work shoes glasses and gloves will be used \\
\hline FM11 & Visual warning form is hanged on the line. Protective work shoes and gloves will be used. Make sure that the ground is dry. \\
\hline FM12 & Visual warning form is hanged on the line. Protective work shoes glasses and gloves will be used \\
\hline
\end{tabular}


Informing the employees and increasing their awareness are important in all occupational health and safety issues. For this reason, a training program for operators has been established. During the training, protective equipment and their importance are repeated and the importance of using equipment for potential risks is discussed. In order to increase the awareness of the employees and to keep in mind the importance of the subject, visual warning forms were hung on various parts of the line. In order to maintain improvement work on occupational health and safety issues, it was decided to obtain management support to provide regular information about near miss, close accidents and unsafe acts parameters from employee data to the leader of $\mathrm{S}$ pillar.

\section{Conclusion}

The TPM is a common philosophy that addresses the methods that many manufacturing enterprises take into account while managing their operations in a systematic manner. Tasks performed during TPM applications are managed with the help of pillars and these pillars are in an interactive relationship with each other. AM and S pillars describe two of the eight application pillars in the TPM structure and are the subject of this study.

The TPM is based on the activities to be done to increase the effectiveness of the equipment on the basis of the application. AM pillar manage the activities that involve daily maintenance repairs by machine operators. With the guidance of AM pillar, machine operators perform cleaning lubrication and control operations for the equipment. This process makes easier to detect when equipment problems are visible, and so the life of the equipment increases. However, there are some occupational health and safety risks where operators are likely to encounter during the realization of these activities. S pillars are activated at this point and perform risk analysis for tasks defined by AM pillar.

There are many techniques for risk assessment. FMEA is a more preferable method because it takes into account the severity, occurrence and detection values. The main area of use of the FMEA method is the detection of product, process and service failure encountered in the production area, but is also used in risk assessment processes.
Fuzzy-based FMEA is a method that can be applied if decision makers are affected by linguistic factors in determining risk factors. In this study, the opinions of four different decision makers were taken to determine the occupational health and safety risks that may be encountered during the AM activities, including the maintenance manager, the AM pillar leader, the machine operator and the S pillar leader. Fuzzy based FMEA method is used for the answers of these decision makers.

The matrix, which is the linguistic variables created by fuzzy logic, was first converted to fuzzy numbers and then a total fuzzy matrix was obtained. Then, after defuzzication of the total fuzzy matrix, the decision matrix was reached. In order to determine the weights of the risk factors in this matrix, entropy technique which is the objective weighting method has been applied. The results were determined as entropy weighted fuzzy FMEA and classical fuzzy FMEA and compared with each other.

The results of the modifications made in order to eliminate the disadvantageous points of the classical fuzzy FMEA method have similarities in the high priority types of errors. However, in cases where uncertainty is more common and less priority situations are differentiated. Therefore, it is seen that fuzzy logic approach is effective in uncertainty environment and in situations where decision makers cannot agree.

The use of fuzzy approach is important for the purpose of promoting the FMEA method, which is frequently referred to in the studies, in also uncertanity conditions. In addition, FMEA has been used in conjunction with a number of multi-criteria decision-making techniques, but not with fuzzy entropy for autonomous maintenance activity safety risks. For this reason, this study differs from the others, in terms of enabling the use in the industry while being a new application study in the field. In order to improve the study and to see more reflections of the effect of the fuzzy approach on the results, it is recommended to carry out applications by taking into consideration the opinions of the decision makers who are contradictory in the future studies. In addition, it can be said that more uncertain results will be obtained and the differences will be determined cases where uncertainty is higher. 


\section{References}

Alcan, P., Balin, A., \& Başlıgil, H., (2013). Fuzzy Multicriteria Selection among Cogeneration Systems: A Real Case Application. Energy Build, 67: 624-634.

Bao, J., Johansson, J., \& Zhang, J. (2017). An Occupational Disease assessment of the Mining Industry's Occupational Health and Safety Management System Based on FMEA and an Improved AHP Model. Sustainability, 9(1), 94.

Braglia, M. (2000). MAFMA: Multi-Attribute Failure Mode Analysis. International Journal of Quality \& Reliability Management, 17(9), 1017-1033.

Braglia, M., Frosolini, M., \& Montanari, R. (2003). Fuzzy TOPSIS Approach For Failure Mode, Effects and Criticality Analysis. Quality and Reliability Engineering International, 19(5), 425-443.

Chang, C. L., Liu, P. H., \& Wei, C. C. (2001). Failure Mode and Effects Analysis Using Grey Theory. Integrated Manufacturing Systems, 12(3), 211-216.

Chang, C. L., Wei, C. C., \& Lee, Y. H. (1999). Failure Mode and Effects Analysis Using Fuzzy Method and Grey Theory. Kybernetes, 28(9), 1072-1080.

Chen, C. C. (2013). A Developed Autonomous Preventive Maintenance Programme Using RCA and FMEA. International Journal of Production Research, 51(18), 5404-5412.

Chin, K. S., Wang, Y. M., Poon, G. K. K., \& Yang, J. B. (2009). Failure Mode and Effects Analysis by Data Envelopment Analysis. Decision Support Systems, 48(1), 246-256.

Chong, K. E., Ng, K. C., \& Goh, G. G. G. (2015). Improving Overall Equipment Effectiveness (OEE) through Integration of Maintenance Failure Mode and Effect Analysis (maintenance-FMEA) in a Semiconductor Manufacturer: A Case Study. In 2015 IEEE International Conference on Industrial Engineering and Engineering Management (IEEM) (14271431). IEEE.

Dağsuyu, C., Göçmen, E., Narlı, M., \& Kokangül, A. (2016). Classical and Fuzzy FMEA Risk Analysis In a Sterilization Unit. Computers \& Industrial Engineering, 101, 286-294.

Eti, M. C., Ogaji, S. O. T., \& Probert, S. D. (2004). Implementing Total Productive Maintenance in Nigerian Manufacturing Industries. Applied energy, 79(4), 385-401.

Eti, M. C., Ogaji, S. O. T., \& Probert, S. D. (2007). Integrating Reliability, Availability, Maintainability and Supportability with Risk Analysis for Improved Operation of the AFAM Thermal Power-Station. Applied Energy, 84(2), 202-221.

Garcia, P. A. A., Schirru, R., \& Frutuoso Emelo, P. F. (2005). A Fuzzy Data Envelopment Analysis Approach for FMEA. Progress in Nuclear Energy, 46(3-4), 359.

Hu, Y., Wu, S. \& Cai, L. (2009). Fuzzy Multicriteria Decision Making TOPSIS for Distribution Center Location Selection. 2009 International Conference on Networks Security, Wireless Communications and Trusted Computing (Vol. 2, pp. 707-710). IEEE.
Ilangkumaran, M., Shanmugam, P., Sakthivel, G., \& Visagavel, K. (2014). Failure Mode and Effect Analysis Using Fuzzy Analytic Hierarchy Process. International Journal of Productivity and Quality Management, 14(3), 296-313.

Immawan, T., Sutrisno, W., \& Rachman, A. K. (2018). Operational Risk Analysis with Fuzzy FMEA (Failure Mode and Effect Analysis) Approach (Case Study: Optimus Creative Bandung). In MATEC Web of Conferences (Vol. 154, p. 01084). EDP Sciences.

Jamshidi, A., Rahimi, S. A., Ait-Kadi, D., \& Ruiz, A. (2015). A Comprehensive Fuzzy Risk-Based Maintenance Framework for Prioritization of Medical Devices. Applied Soft Computing, 32, 322-334.

Keay, E. \& Borycki, E. (2010). Methods to Assess the Safety of Health Information Systems. Healthcare Quarterly, 13(Special issue), 47-52.

Kutlu, A., C. \& Ekmekçioğlu, M. (2012). Fuzzy Failure Modes and Effect Analysis by Using Fuzzy TOPSIS-Based Fuzzy AHP. Expert System with Applications, 39(1), 61-67.

Liu, H. C. (2016). FMEA Using Uncertainty Theories and MCDM Methods. In FMEA Using Uncertainty Theories and MCDM Methods (13-27). Springer, Singapore.

Liu, H. C., Liu, L., Liu, N., \& Mao, L. X. (2012). Risk Evaluation in Failure Mode and Effects Analysis with Extended VIKOR Method under Fuzzy Environment. Expert Systems with Applications, 39(17), 12926-12934.

McKone, K. E., \& Weiss, E. N. (1998). TPM: planned and Autonomous Maintenance: Bridging the Gap between Practice and Research. Production and operations management, 7(4), 335-351.

Nakajima, S. (1988). Introduction to TPM. Productivity Press, Cambridge, MA.

Ostadi, B., \& Saifpanahi, H. (2017). A Practical Self-Assessment Framework for Evaluation of Maintenance Management System based on RAMS Model and Maintenance Standards. Journal of Industrial and Systems Engineering, 10, 125-143.

Özveri, O., \& Kabak, M. (2015). The Usage of MCDM Techniques in Failure Mode and Effect Analysis. Journal of Economics and Management Research, 4(2), p94-108.

Pomorski, T. R. (2004). Total Productive Maintenance (TPM) Concepts and Literature Review. Brooks Automation, 1-110.

Rodrigues, M., \& Hatakeyama, K. (2006). Analysis of the Fall of TPM in Companies. Journal of Materials Processing Technology, 179(1-3), 276-279.

Salehi, M. \& Tavakkoli-Moghaddam, R. (2008). Project Selection by Using a Fuzzy TOPSIS Technique. World Academy of Science, Engineering and Technology, 40, 85-90. 
Sanayei, A., Mousavi, S.F. \& Yazdankhah, A. (2010). Group Decision Making Process for Supplier Selection with VIKOR under Fuzzy Environment. Expert Systems with Applications, 37(1), 24-30.

Sarı, E. B. Toplam Verimli Bakım Uygulayan Bir İşletmede Bakım Personelinin Performans Değerleme Puanlarının Entropi Tabanlı ViKOR Sıralaması ile Karşılaştııılması. İşletme Bilimi Dergisi, 5(3), 59-78.

Selim, H., Yunusoğlu, M. G., \& Yılmaz Balaman, Ş. (2016). A Dynamic Maintenance Planning Framework Based on Fuzzy TOPSIS and FMEA: Application in An International Food Company. Quality and Reliability Engineering International, 32(3), 795-804.

Shaikh, A., \& Mettas, A. (2010). Application of Reliability, Availability, and Maintainability Simulation to Process Industries: A Case Study. In Simulation Methods for Reliability and Availability of Complex Systems (173-197). Springer, London.

Shannon, C.E., \& Weaver, W., (1947). A Mathematical Theory of Communication, The University of Illinois Press, Urbana.

Sharma RK, \& Sharma P. (2010). System Failure Behavior and Maintenance Decision Making Using, RCA, FMEA and FM. Journal of Quality in Maintenance Engineering, 16 (1), $64-88$.

Sharma, R. K., Kumar, D., \& Kumar, P. (2007). Modeling and analysing system failure behaviour using RCA, FMEA and NHPPP models. International Journal of Quality \& Reliability Management.

Sharma, R. K., \& Kumar, S. (2008). Performance Modeling Critical Engineering Systems Using RAM Analysis. Reliability Engineering \& System Safety, 93(6), 913-919.

Sharma, R. K., Kumar, D., \& Kumar, P. (2005). Systematic Failure Mode Effect Analysis (FMEA) Using Fuzzy Linguistic Modelling. International Journal of Quality \& Reliability Management, 22(9), 986-1004.

Sharma, R. K., Kumar, D., \& Kumar, P. (2007). Modeling and Analyzing System Failure Behaviour Using RCA, FMEA and NHPPP Models. International Journal of Quality \& Reliability Management, 24(5), 525-546.
Shirose, K. (1992). TPM for Operators. Portland, OR, Productivity Press.

Singh, R., Gohil, A. M., Shah, D. B., \& Desai, S. (2013). Total Productive Maintenance (TPM) Implementation in A Machine Shop: A Case Study. Procedia Engineering, 51, 592-599.

Souza RQ, \& Álvares AJ. (2008). FMEA and FTA Analysis for Application of Reliability-Centered Maintenance Methodology: Case Study on Hydraulic Turbines. ABCM Symposium Series in Mechatronics 2008, 3 :803 - 812.

Stamatis, D. H. (2003). Failure Mode and Effect Analysis: FMEA From Theory to Execution. ASQ Quality press.

Tajiri, M., \& Gotoh, F. (1992). TPM implementation, a Japanese approach. New York, NY: McGraw-Hill.

Tay, K. M., \& Lim, C.P., (2006). Fuzzy FMEA with A Guided Rules Reduction System for Prioritization of Failures. International Journal Quality Reliability Management. 23(8), 1047-1066.

Venkatesh, J. (2007). An Introduction to Total Productive Maintenance (TPM). The Plant Maintenance Resource Center, 3-20.

Wakjira, M. W., \& Singh, A. P. (2012). Total Productive Maintenance: A Case Study in Manufacturing Industry. Global Journal of Research In Engineering, 12(1-G).

Wang, Y.M., Chin, K.S., Poon, G.K.K., \& Yang, J.B., (2009). Risk Evaluation In Failure Mode and Effects Analysis Using Fuzzy Weighted Geometric Mean. Expert Systems with Applications, 36(2), 1195-1207.

Yadav, O. P., Singh, N., Goel, P. S., \& Itabashi-Campbell, R. (2003). A Framework for Reliability Prediction during Product Development Process Incorporating Engineering Judgements. Quality Engineering, 15(4), 649-662.

Zadeh, L.A. (1965). Fuzzy Sets. Information and Control, 8, 338383.

Zadeh, L.A. (1975). The Concept of Linguistic Variable and Its Application to Approximate Reasoning. Information Sciences, 8, 199-249.

Zeng, S. X., Tam, C. M., \& Tam, V. W. (2010). Integrating Safety, Environmental and Quality Risks for Project Management Using a FMEA Method. Engineering Economics, 66(1), 4452. 